\title{
BASIC CHARACTERISTICS OF STUDENTS IN THE SYSTEM OF SCHOOL EDUCATION ON NATIONAL LEVEL AND BY MAIN REGIONS AND CITIES IN BULGARIA
}

\author{
R. Radev* \\ University of National and World Economy, Sofia, Bulgaria
}

\begin{abstract}
The main goal of the current publication is to present the specific characteristics of students in the system of school education. The methodological framework through which the goal is achieved consists of four steps: first - the total number of schools and their number by types (general, vocational and special) is identified; second - the number of students and their structure in basic and high general schools is given; third the number of vocational schools - total and by types, as well as the students enrolled in them; fourth - languages learnt in basic and high schools in Bulgaria; also, the number of students graduating from general and vocational schools on national level and by main cities and regions. The conclusion from the study is that identifying the number and characteristics of students enrolled in the school education is a very important part of the Human resource sustainable capacity evaluation on national level and by cities and regions. The HR sustainable capacity is evaluated from the point of the number of graduating students and their technical and language skills. This analysis is also important to the universities in Bulgaria and abroad because it helps evaluating the number of applying students in short, middle and long-term period.
\end{abstract}

Key words: general schools, vocational schools, language skills, HR capacity sustainability, PESTEL analysis

\section{INTRODUCTION}

The current publication represents part of the results from a complex study through which the human resource capacity of Bulgaria is identified as an important outsourcing destination. The main goal of this study was to identify the opportunities for business growth of the outsourcing companies in Bulgaria. Three main groups of people were identified as factors which form the sustainability of the Human resource capacity - people, employed in outsourcing companies in Bulgaria and in companies from the IT sector; young work force of the age 15-39 years; students graduating their high schools (basic and

\footnotetext{
*Correspondence to: Assoc. prof. Dr. Radko Radev, University of National and World Economy, Sofia, Bulgaria, radko_radev@unwe.eu, 0894780098
}

vocational) and students enrolled in the system of tertiary education. The subject of interest in this paper is the sustainability of the HR Capacity formed by the students graduating from their high schools. Their count is about 45 thousand people which is approximately $5 \%$ of the young work force (15-39 years old). Their distribution is not even through the country.

The main goal of the current paper is to identify the importance of the graduating students as a main factor of the HR Sustainable Capacity. This goal is achieved by completing the next main objectives: 1) Presenting the methodological framework; 2) Presenting the type of schools and their number; 3) Defining the number of graduating students - total and by types of schools; 4) The geographical distribution is completed. In conclusion the main 
cities from the point of view of their HR capacity sustainability are identified.

The assessment of HR capacity sustainability is a key component in decision-making for business growth. (1, 2) The importance of Human resource management is a result from core understanding that it plays main role for the success of business organizations. (3) This role has been confirmed by different schools and researchers. (4) Human resources should be managed in accordance with the organization's strategy and to be accepted as an integral part of every manager's work. $(5,6)$ Human resource management also needs strategic orientation. (7, 8) This understanding is the heart of the concept well known as "human resources" and "human capital". (9)

The narrow perception is that the human resource management considers its functions only the ones which fall within the boundaries of business organizations. (10) According the broader perception functions of human resource management go beyond the boundaries of business organizations. (11) The perception of human resources in this way is in the core of understanding the means and the roles of HR Capacity and Sustainability a key component in strategic decision-making process.

\section{METODOLOGY}

The methodological framework through which the goal is achieved consists of fifth steps. first the system of education and the place of school education is presented through graphic scheme; second - the total number of schools and their number by types (general, vocational and special) is identified; third - the number and structure of students in basic and high general schools is given; forth -the number of vocational schools - total and by types as well as the students enrolled in them; fifth - the number of students graduating from general and vocational schools on national level and by main cities and regions. This framework is a part of more complex methodology which use a deductive approach

- The first step in this approach starts with general overview of the country competitiveness, macro environmental factors and the way they impact outsourcing business.

- The next step is generating a general notion for Bulgarian population with its main demographic characteristics. Four main groups of people, forming the country's HR Sustainable capacity, are identified:

- working young people - people of age between 15-39;

- groups of employed in activities close to outsourcing;

- current employees, working in other outsourcing companies;

- $\quad$ students graduating their secondary schools and these ones enrolled in higher education.

- During the third step these groups are analyzed in depth to define the individual potential of each of them as well as their overall potential. The analysis is performed for the country as a whole and also for the different administrative regions, districts and cities.

- The complex HR Sustainable capacity assessment is made for the country on the one hand and on the other hand for the separate territories. As a result of this evaluation, the prioritization of separate territories is carried out.

\section{RESULTS}

The Bulgarian educational system falls within the continental European tradition. The main types of secondary schools are: general educational, vocational, language schools and foreign schools. Private schools are also being established and they are beginning to compete successfully with state schools.

There are three main type of schools in Bulgaria - general, vocational and special. The total number of schools is 2505. From them 1990 are general, 454 are vocational and 61 are special. (Figure 1)

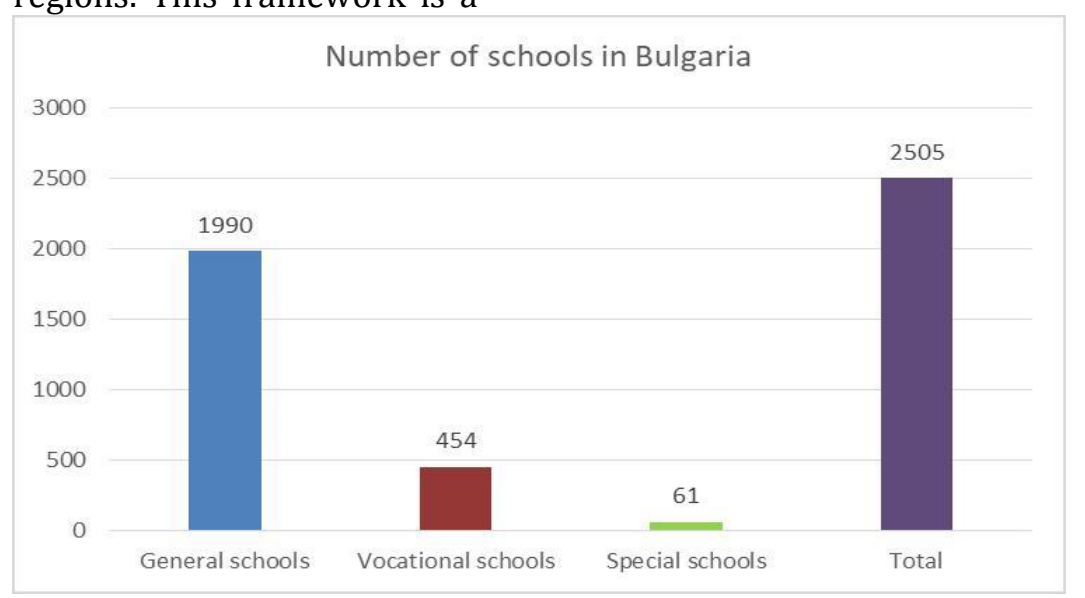

Figure 1. Number of schools - total and by type 
1. Students in basic and high general schools

The students were 605700 as a whole for 2016, of which: 263'200 were enrolled in I IV grade; 213,500 in V-VIII grade and $129^{\prime} 000$ in IX-XIII grade. It is seen from the
$R A D E V R$.

figures bellow that the increase in the total number of students in general schools is a result of increase observed in group of I -IV grade. (Figure 2) There were 22 pupils on average for one class in the daily general education schools.

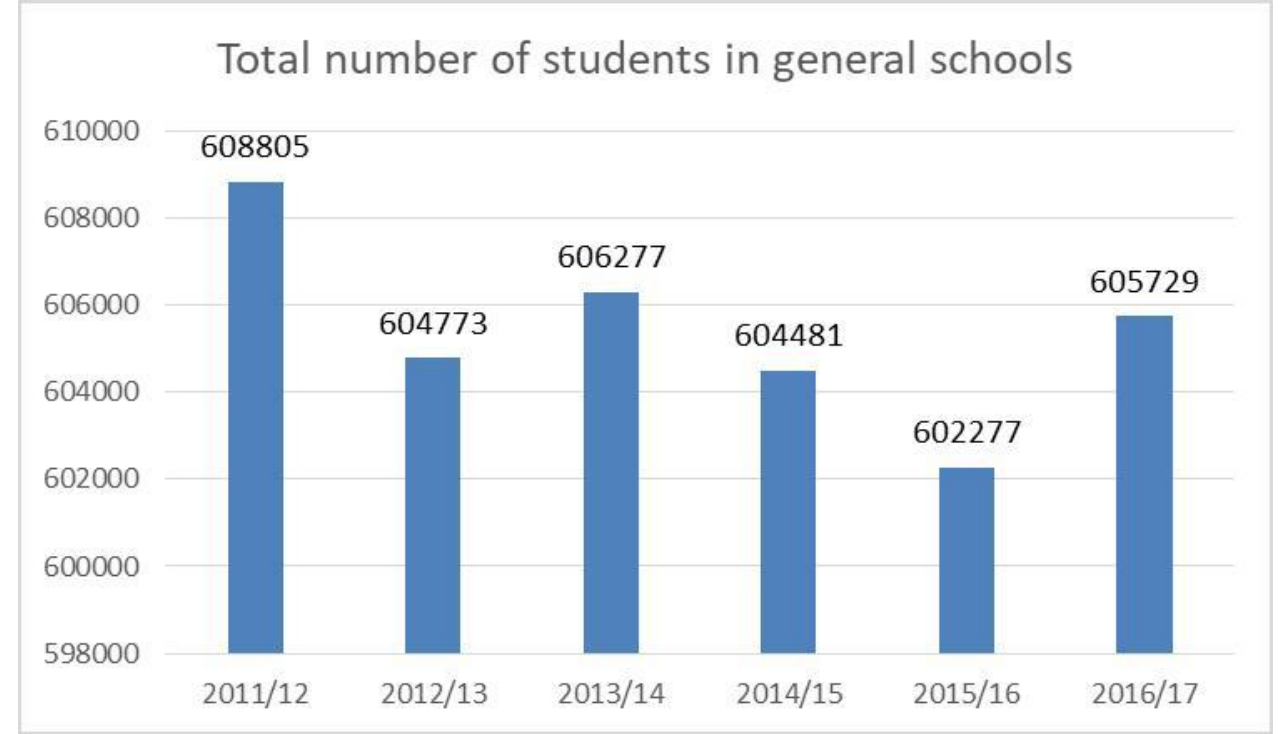

Figure 2. Enrolments in genera education schools by groups and grades

Graduating students in general schools by regions (NUTS2 and NUTS3 and 9 main cities) From the four graphics bellow become clear what is the number of graduate students in the three different levels (regions) - NUTS -2, NUTS -3 and 9 main cities of interest. It can be seen that in NUTS 2 level, the region with the biggest number is Northwest with its 8022 graduate students annually. The main reason for the leading position is that in this region is included Sofia, where are more than 5 thousands graduating students. (Figure 3)

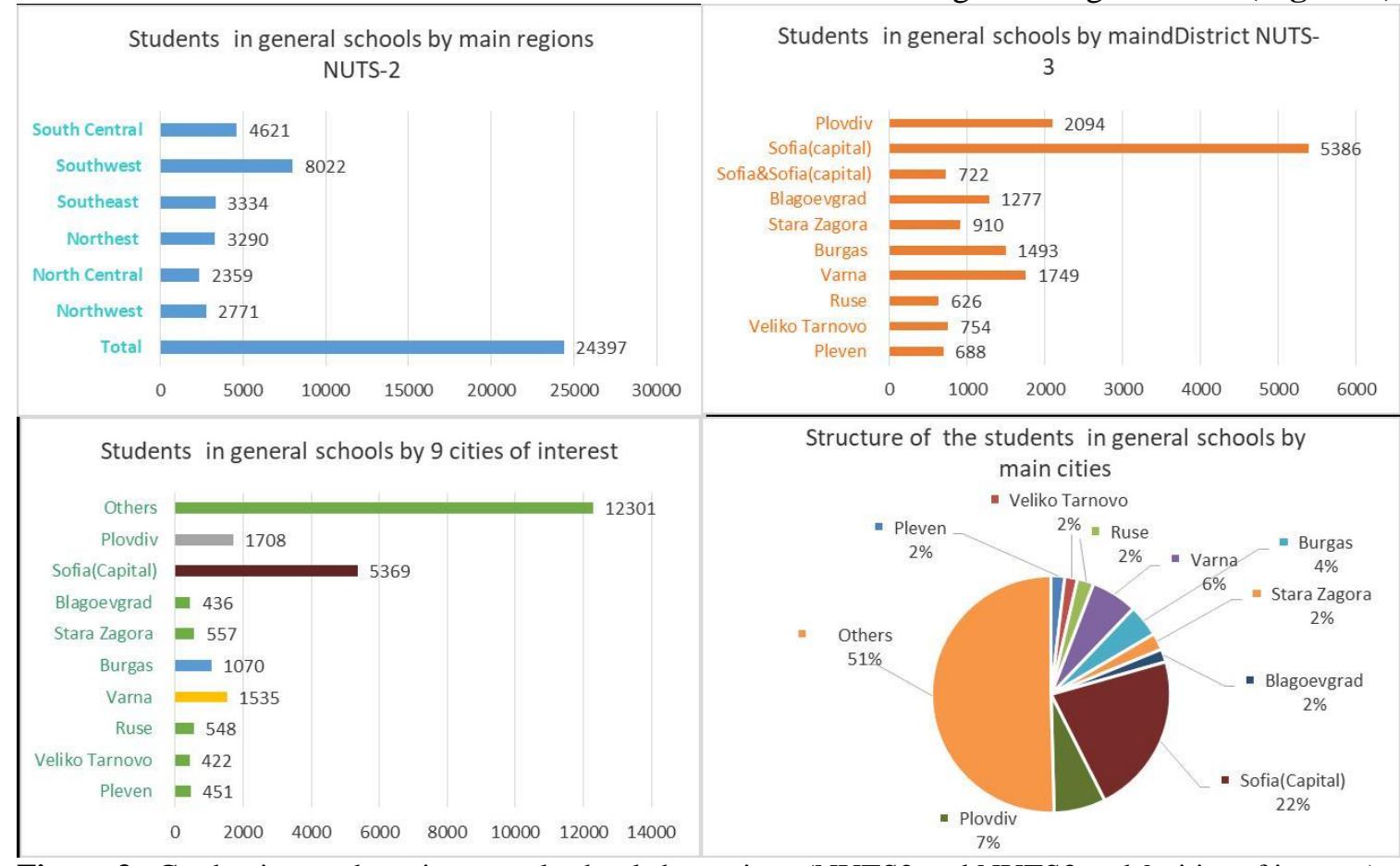

Figure 3. Graduating students in general schools by regions (NUTS2 and NUTS3 and 9 cities of interest)

The next NUTS 2 region by the number of students graduating per year, which is 4621 , is South Central. The third and the fourth places are taken by Southeast and Southwest regions with
3444 and 3290 graduating students, followed by Northwest - 2771 and North central.

The graduating students in the examined NUTS 3 regions consist mainly from these ones enrolled 
in the districts which centers are nine major cities that are of particular interest in the current research. From 6090 graduating students in Sofia district region, which is leading one from all NUTS 3 regions, $88 \%$ conducting their high degree education in Sofia (Capital). The situation is the same with the rest eight cities as centers of the corresponding regions. In the city of Plovdiv are enrolled $82 \%$ of the graduating students in the Plovdiv district. The others districts with the similar weight of their central cities are Varna (1535 or $88 \%$ of 1749 ) and Rousse (548 or $87 \%$ of 626). (Figure 3)

In the other districts the weight of their centers in the number of the total graduating students is lower. These are the cases with Blagoevgrad, Stara Zagora, Veliko Tarnovo, Burgas. In
Blagoevgrad there are only 436 or $34 \%$ of all 1277 graduating students in the eponymous district. From 1493 graduates in Burgas districts, 1070 or $72 \%$ are studying their last year in the city itself. The percentage of students who are studying the last year in high schools in Veliko Tarnovo is $54 \%$ of all 910 in its district and this one in Stara Zagora -557 or $61 \%$ of 910 .

\section{Students in vocational schools 2.1. The number of vocational schools - total and by types}

Vocational education and training during the school year 2016/2017 was carried out 454 of which: 22 art schools, 24 sport schools, 373 vocational gymnasiums and 35 vocational colleges with enrolment after secondary education. (Figure 4)

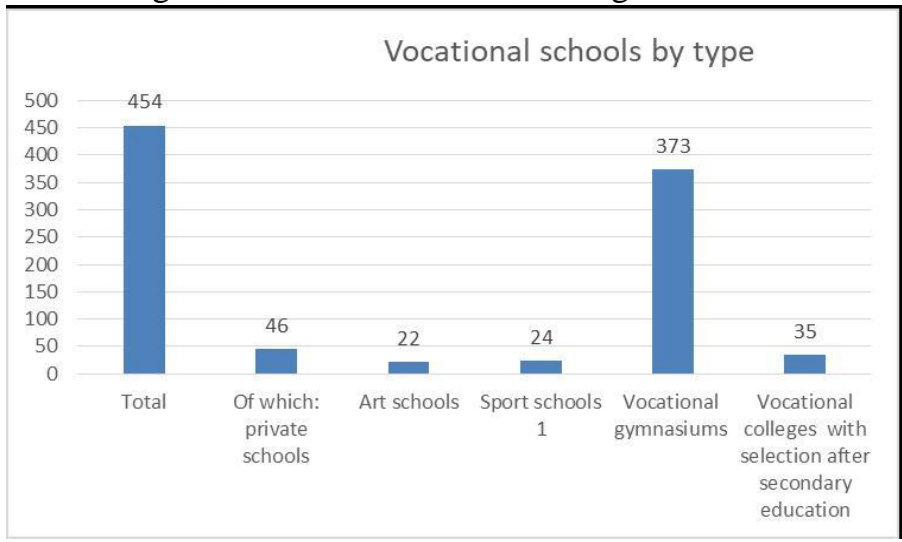

Structure od vocational schools by type

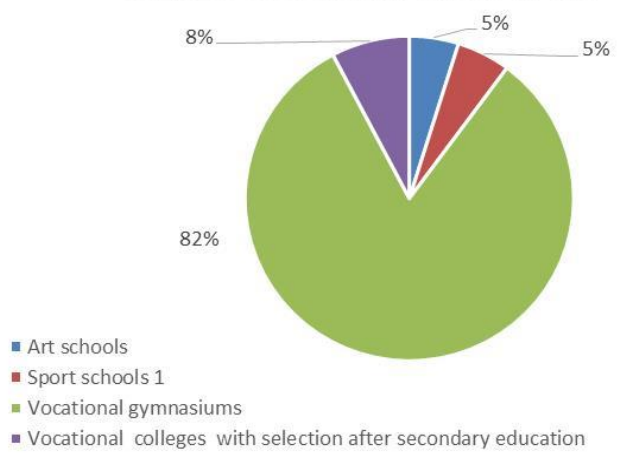

Figure 4. Vocational education and training during the school year 2016/2017

The total number of students in there was 131 '436 and in comparison with the previous year decreased by 4' 100 or by $3.1 \%$. The majority of the students enrolled in the vocational schools in Bulgaria learn in vocational gymnasiums (third level). They counts 90'221,

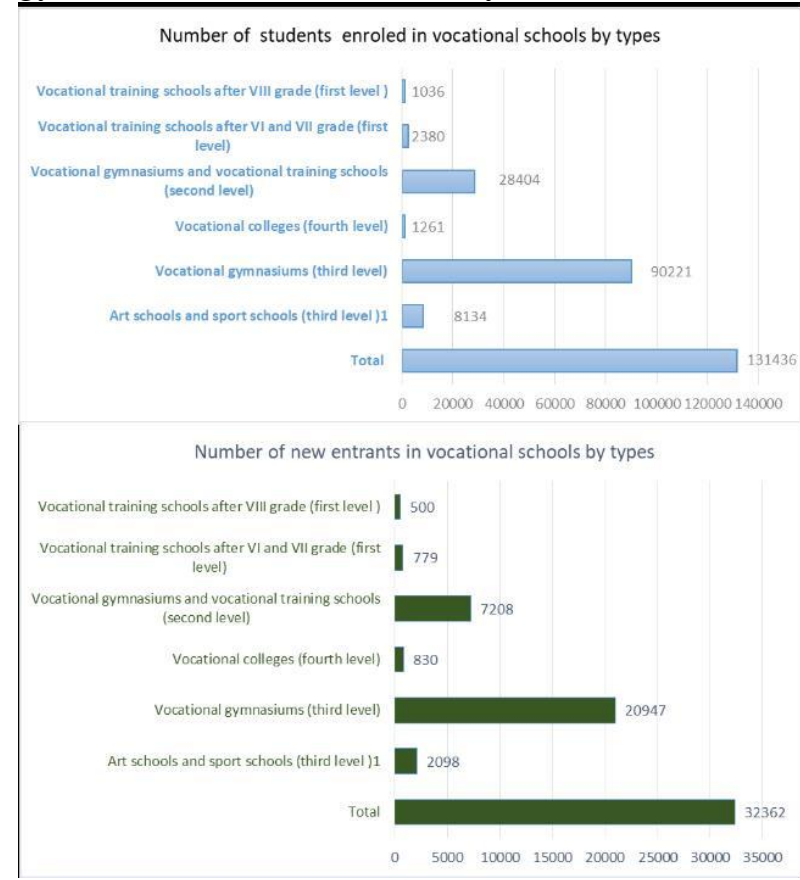

which represents $69 \%$ of the total. Next important part are the students who learn in vocational gymnasiums and vocational training schools (second level) - their number is $28^{\prime} 404$ or $21 \%$ of all enrolled in vocational schools.

(Figure 5)

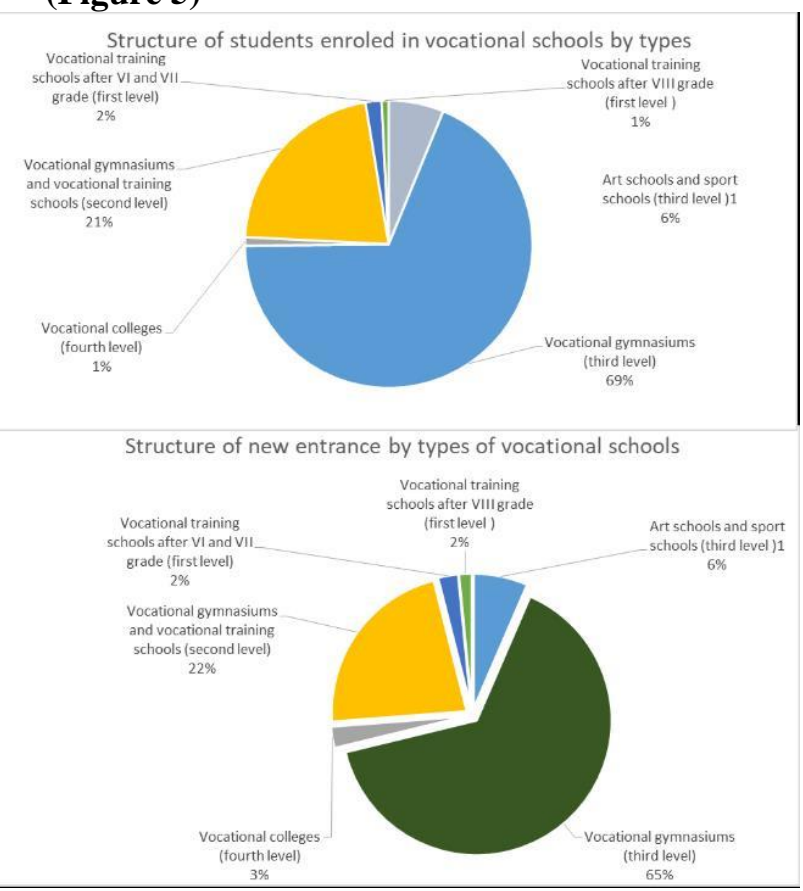

Figure 5. Number and structure of students enrolled in vocational schools 
The number of newcomers is 32,362 from whom $65 \%$ or $20^{\prime} 947$ enter into vocational gymnasiums (third level) and 22\% (7'208) into vocational gymnasiums and training schools.

2.2. Graduating students in vocational schools by regions.

Total graduating students at vocational schools count almost 20,578 . From them $77 \%$ or

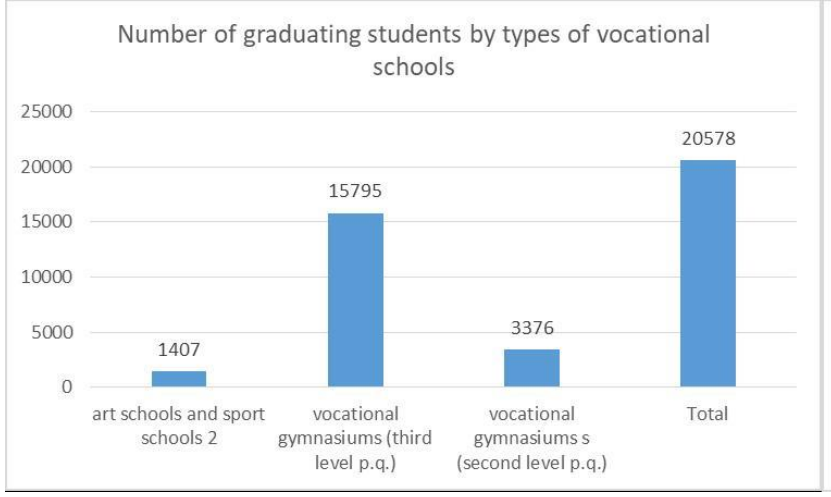

$R A D E V R$.

$\left.15^{\prime} 795\right)$ graduate from vocational gymnasiums with third level of professional qualification. Next group of students are these ones who graduate with second level of professional qualification. This group counts $16 \%$ and counts 3'376. The smallest number of student (1'407, or 7\%) graduate from art and sport schools. (Figure 6)

Figure 6. Number and percentage of graduating students by types of vocational schools

With its 5, 400 who graduate there, the biggest part $(26 \%)$ or graduating vocational schools on the level NUTS -2 is taken by Southwest region. In South central regions vocational schools are graduated by 4' 040 students,

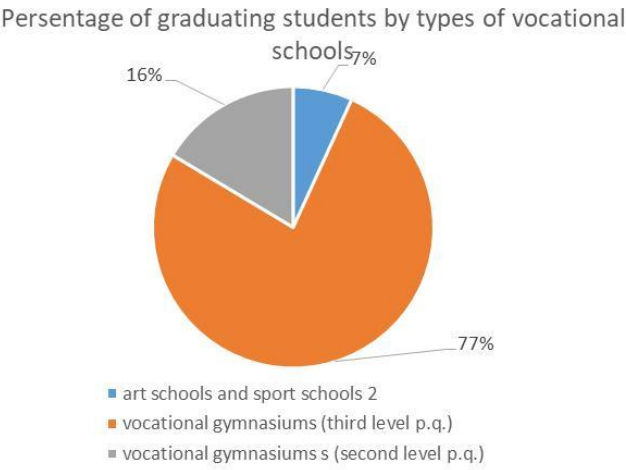

Persentage of graduating students by types of vocational

which represent $20 \%$ of the total. In the next four NUTS-2 regions graduating students varies between 2'293 and 3'321 and share of the total between 11 to $16 \%$. (Figure 7)

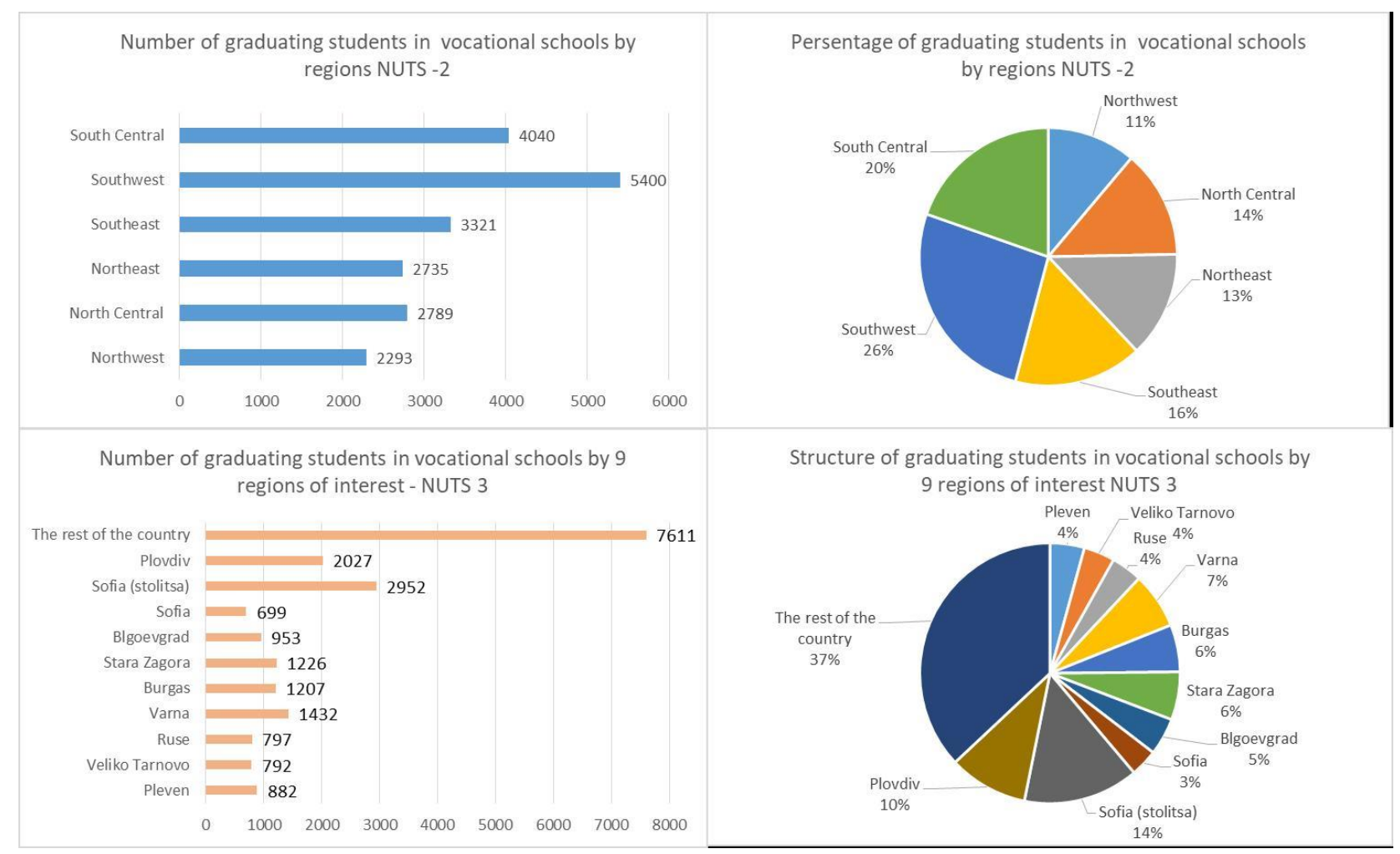

Figure 7. Number and percentage of graduating students by regions NUTS -2 and NUTS-3

Looking at the NUTS 3 regions, it is clear that the largest proportion of students graduate in the Sofia capital - almost 3' 00 , or $14 \%$. Adding to them graduates in Sofia district 699 , the share of Sofia increase to $19 \%$. The only other city with above 2'000 graduating vocational gymnasiums is Plovdiv district, which share of the total is $10 \%$. The regions with more than 1'000graduating students are 3 - Varna, Stara Zagora and Rousse. Totally in 
the nine regions of interest graduate $63 \%$ of the total students graduating from vocational gymnasiums versus $37 \%$ for the rest part of the country.

Results from analyzing the 9 cities of interest reproduce in big extent the picture observed in regions NUTS -3 level. The city with the
$R A D E V R$.

biggest number of graduating students is again Sofia (capital) without having any reduction of its value. The second place is for Plovdiv where graduating from vocational schools are 1'471. This represents $73 \%$ of the students in Plovdiv districts (NUTS-3).

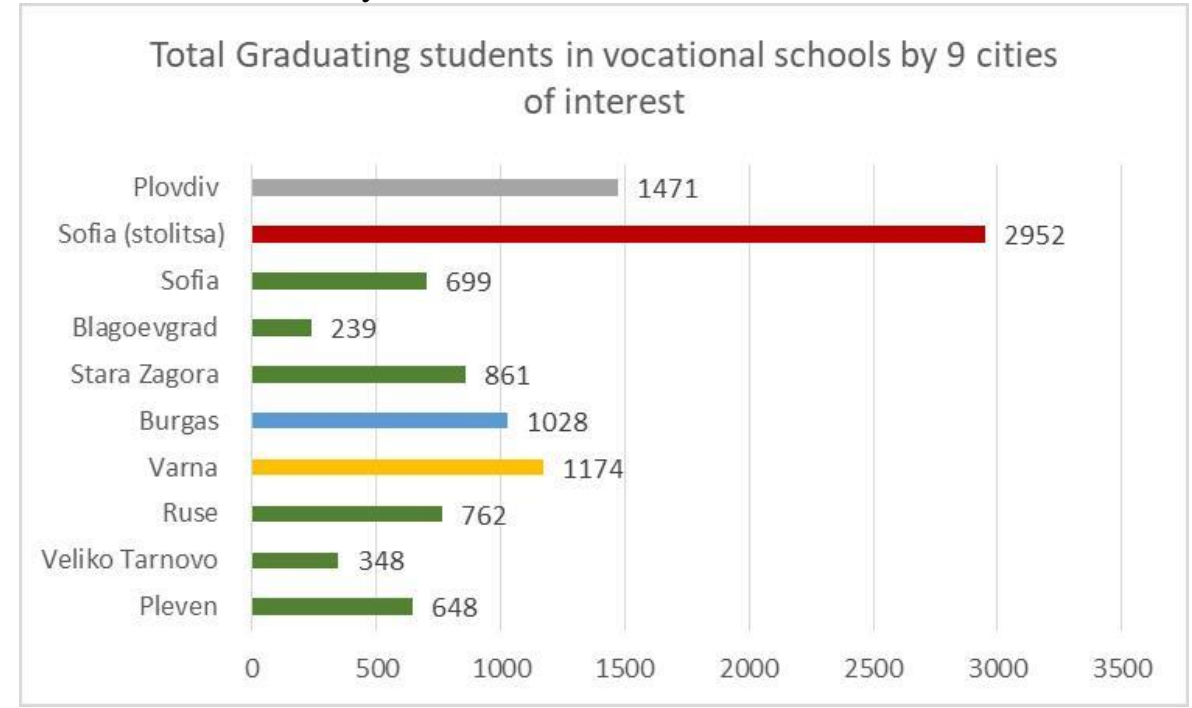

Figure 8. Total graduating students in vocational schools by 9 cities of interest

In the city of Varna there are 1'174 students graduate from vocational schools which is $82 \%$ of the total 1'432 in Varna district. Next cities are: Burgas with its 1028 or $85 \%$ of graduating from vocational schools in Burgas districts; Stara Zagora (861 or $70 \%$ of the district) etc. (Figure 8)

\section{Graduating students at all type of secondary schools}

3.1. Graduating students in Bulgaria - total and by types of high schools

As can be seen from the figures bellow the total number of graduating students from

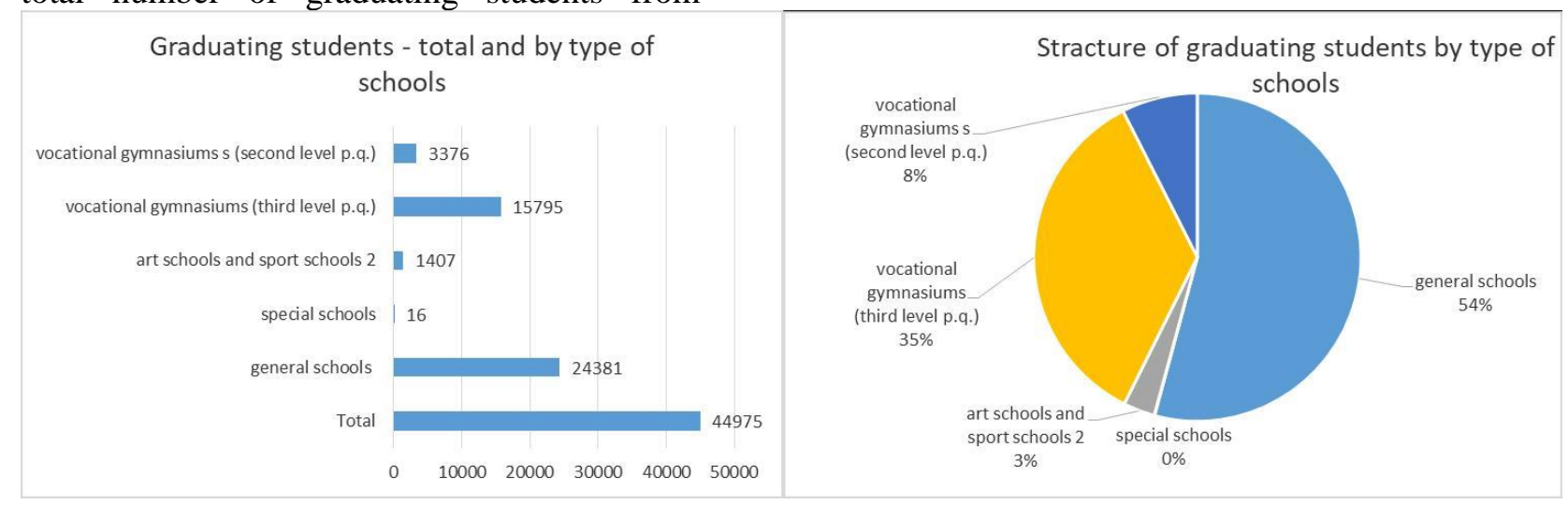

Figure 9. Graduating student in all types of schools

3.2. Graduating students by regions and cities of interest

In Sofia (capital) and Sofia district the total number of students who graduate from secondary schools of education is $44^{\prime} 950$. The biggest part of them $-54 \%$ or 24 '381graduate from general schools. The next important types of school, where graduate almost 15’795 students, are vocational gymnasiums (third level of professional qualification). Their share of the total graduating student is $35 \%$. The number of the student who graduate from another types of schools is significantly smaller. Vocational gymnasiums (second level) are graduated by 3'376, or $8 \%$ of all graduating students in Bulgaria. (Figure 9) 
graduating students takes $9 \%$ share. Varna and Burgas are next important districts where
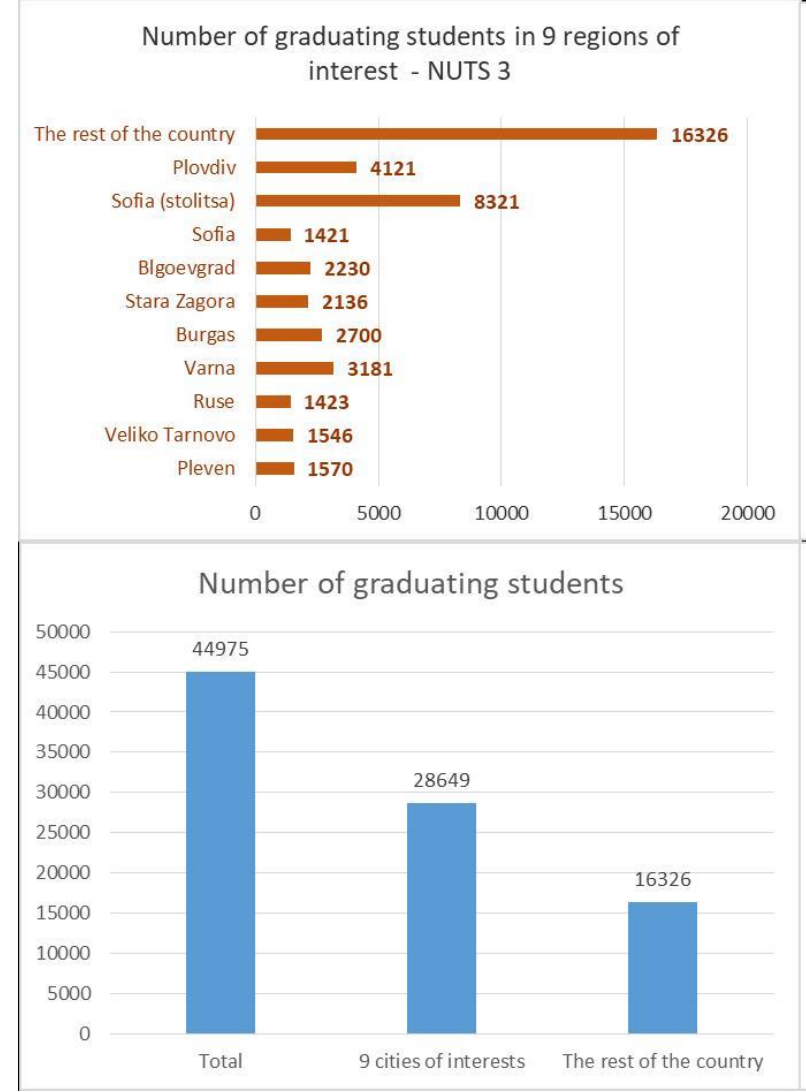

Figure 10. Graduating students by totally and by nine regions of interest NUTS-3

In two of the regions NUTS 3- Stara Zagora and Blagoevgrad - students, graduating their secondary schools, are slightly over 2'000 (or $5 \%$ ). In the rest three cities (Rousse, Velico Tarnovo and Pleven) the students who graduate from high schools are around 1'500. Taken totally, the graduating students in all nine regions of interest are $28^{\prime} 649$. This means that their share of the total graduating students in Bulgaria is $64 \%$. 16'326 students or $36 \%$ graduate in the rest part of the county. graduate respectively $3{ }^{\prime} 181(7 \%)$ and $2{ }^{\prime} 700$ (9\%). (Figure 10)

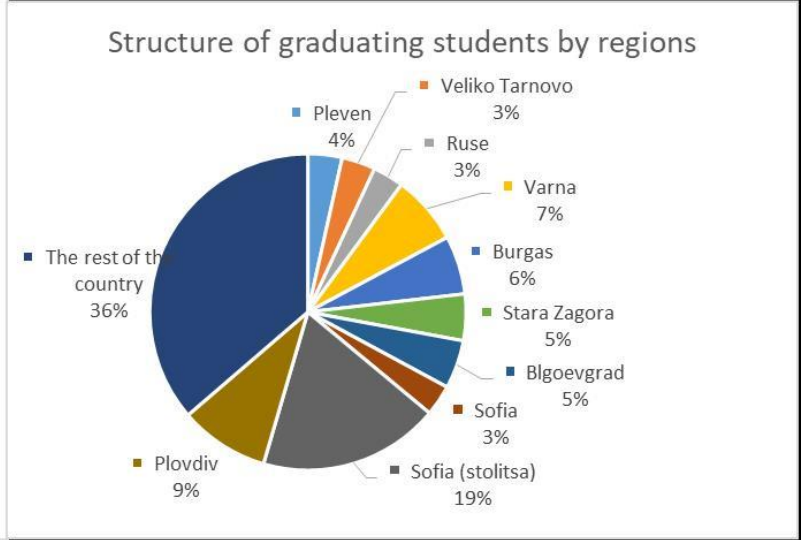

Structure of graduating students

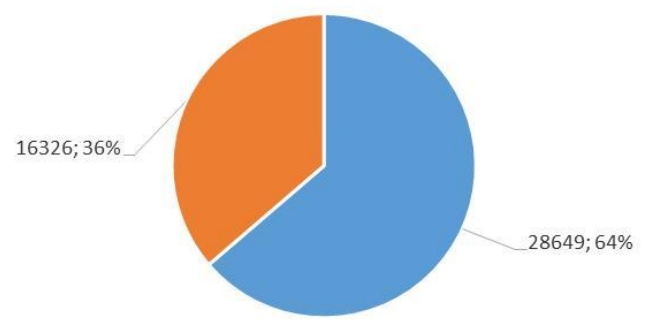

\# 9 cities of interests $\|$ The rest of the country
The data shows that graduating students in Sofia (capital) and Sofia districts are 9'742 and only in Sofia $-8,321$. Plovdiv is on the second place after Sofia - graduating students from high schools in the city of Plovdiv are 3'179. Third place is for Varna - the graduating students from high schools are 2'709. Burgas takes fourth place with 2'098 the graduating students. The next cities are as follows: Stara Zagora - 1418, Rousse - 1310, Pleven - 1099 and Veliko Tarnovo - 770, Blagoevgrad - 675 graduating students.

\section{(Figure 11)}
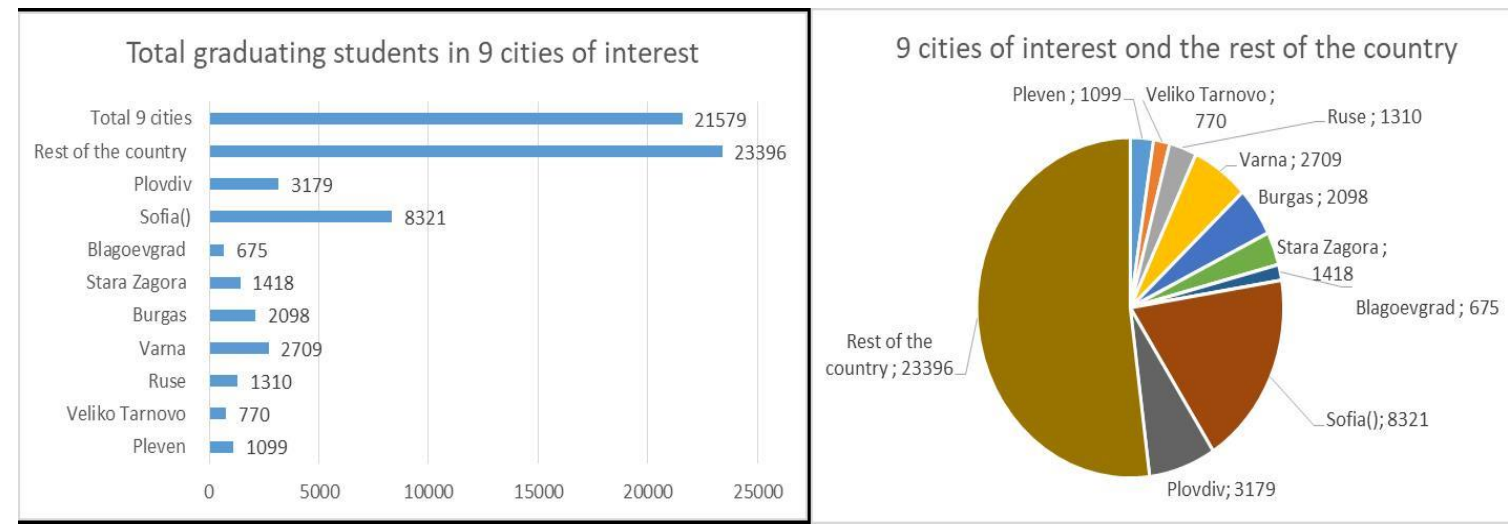

Figure11. Total graduating students in the 9 main cities 


\section{CONCLUSIONS}

A very important part of the HR capacity sustainable evaluation is the number of students graduating annually from secondary schools. The analysis is conducted for each one of the nine cities of interest and for the whole country. This helps outsourcing companies to define where (to which cities) to focus their further researches. The city with greatest potential in HR Capacity sustainability is Sofia. Graduating students from secondary schools here form $18 \%$ of the total for the country. The grads in Plovdiv are 2.6 times less than those in Sofia or $7 \%$ of the total. The number graduating students in Varna is $17 \%$ less than in Plovdiv. Comparing to Varna, there are $30 \%$ less graduating students in Burgas.

Additional research must be done to establish the profile of high schools according their fields of education for every city of interest. Through this research secondary schools where students with desired profile are located will be identified. It is also recommended to conduct a primary representative survey. This will help evaluating the qualitative characteristics of graduating students from their high schools for every single territory and the country itself.

An additional research is needed because there are potentially unknown newcomers for the outsourcing labor market. It is necessary to develop appropriate programs in order to attract these young people. The programs must be addressed directly to youth and/or to the institutions they study at.

\section{REFERENCES}

1. Ehnert, I., Harry, W., Zink, K. J., Sustainability and Human Resource Management: Developing Sustainable Business Organizations. Springer Science \& Business Media, 2013.

2. Ehnert, I., Sustainable Human Resource Management: A conceptual and exploratory analysis from a paradox perspective, Springer Science \& Business Media, 2009.

3. McGregor, D. (1985). The Human Side of Enterprise. (25thanniversary edition) New York: McGraw-Hill, pp. 33-48.

4. Witzel, M., A History of Management Thought, 2-d Edition.Routlege, London and New York, 2016.

5. Fombrun, C.J., Tichy, N.M. and Devanna, M.A., Strategic Human Resource Management. Wiley, New York, 1984.

6. Price, A., HumanResource Management in a Business Context, 2-th Ed. Thompson, 2004.

7. Beer, M., Spector, B., Lawrence, P.R., Quinn Mills, D. and Walton, R.E., Human Resource Management. New York: Free Press, 1984.

8. Kearns, P., HR Strategy: Creating Business Strategy with Human Capital. Routledge, Second edition, ELSEVER, 2010.

9. Schermerhorn, J., R., Introduction to Management, John Wiley \& Sons, 2011.

10.Armstrong,M, A Handbook of Human Resource Management Practice, 10-th edition. Kogan page, London, 2010.

11.Ulrich, D., Brockbank, W., Younger, J., Nyman, M., Allen, J., HR Transformation: Building Human Resources From the Outside In. McGraw Hill Professional, 2009. 